\title{
Expression and characterization of a GH43 endo-arabinanase from Thermotoga thermarum
}

\author{
Hao Shi ${ }^{1,2}$, Huaihai Ding ${ }^{1,2}$, Yingjuan Huang ${ }^{1,2}$, Liangliang Wang ${ }^{1,2}$, Yu Zhang ${ }^{1,2}$, Xun Li ${ }^{1,2}$ and Fei Wang ${ }^{1,2^{*}}$
}

\begin{abstract}
Background: Arabinan is an important plant polysaccharide degraded mainly by two hydrolytic enzymes, endo-arabinanase and $\mathrm{a}-\mathrm{L}$-arabinofuranosidase. In this study, the characterization and application in arabinan degradation of an endo-arabinanase from Thermotoga thermarum were investigated.

Results: The recombinant endo-arabinanase was expressed in Escherichia coli BL21 (DE3) and purified by heat treatment followed by purification on a nickel affinity column chromatography. The purified endo-arabinanase exhibited optimal activity at $\mathrm{pH} 6.5$ and $75^{\circ} \mathrm{C}$ and its residual activity retained more than $80 \%$ of its initial activity after being incubated at $80^{\circ} \mathrm{C}$ for $2 \mathrm{~h}$. The results showed that the endo-arabinanase was very effective for arabinan degradation at higher temperature. When linear arabinan was used as the substrate, the apparent $K_{m}$ and $V_{\max }$ values were determined to be $12.3 \pm 0.15 \mathrm{mg} \mathrm{ml}^{-1}$ and $1,052.1 \pm 12.7 \mu \mathrm{mol} \mathrm{ml}^{-1} \mathrm{~min}^{-1}$, respectively $\left(\mathrm{at} \mathrm{pH} 6.5,75^{\circ} \mathrm{C}\right.$ ), and the calculated $k_{\text {cat }}$ value was $349.3 \pm 4.2 \mathrm{~s}^{-1}$.
\end{abstract}

Conclusions: This work provides a useful endo-arabinanase with high thermostability andcatalytic efficiency, and these characteristics exhibit a great potential for enzymatic conversion of arabinan.

Keywords: Arabinan, Arabinose, Endo-arabinanase, Thermotoga thermarum

\section{Background}

Lignocellulosic biomass, the most abundant renewable carbon resources in the biosphere, has exhibited valuable industrial applications in many fields, such as pulp and paper, food processing, detergent, textile, synthetic biology, organic synthesis, pharmaceuticals and bioenergy production [1,2]. Arabinan, a polysaccharide constituent of hemicellulose, is composed of $\alpha-1,2-$ and/or $\alpha-1,3$-linked to a $\alpha-1,5$-linked L-arabinofuranosyl backbone residues [3-5]. Arabinan mainly consists of L-arabinose residues, existing in rhamnogalacturonan regions of pectins in the cell walls of several plants [6]. Microbial enzymes including hydrolases have represented an important part in industry due to their various favorable properties [7]. To generate Larabinose from arabinan, two major hydrolytic enzymes, endo-arabinanase and $\alpha$-L-arabinofuranosidase, are essential to the synergetic action. Endo-arabinanase (EC 3.2.1.99) can hydrolyze the arabinan $\alpha$-1,5-linked L-arabinofuranosyl

\footnotetext{
* Correspondence: hgwf@njfu.edu.cn

'College of Chemical Engineering, Nanjing Forestry University, Nanjing 210037, China 2Jiangsu Key Lab of Biomass-Based Green Fuels and Chemicals, Nanjing
210037, China 210037, China
}

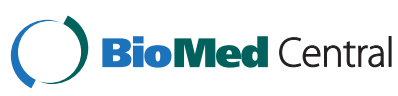

(C) 2014 Shi et al.; licensee BioMed Central Ltd. This is an Open Access article distributed under the terms of the Creative Commons Attribution License (http://creativecommons.org/licenses/by/2.0), which permits unrestricted use, distribution, and reproduction in any medium, provided the original work is properly credited. The Creative Commons Public Domain Dedication waiver (http://creativecommons.org/publicdomain/zero/1.0/) applies to the data made available in this article, unless otherwise stated. backbone to produce arabino-oligosaccharides or Larabinoses, whereas $\alpha$-L-arabinofuranosidase (EC 3.2.1.55) is capable of thoroughly hydrolyzing arabino-oligosaccharides and arabinan side chain substitutions to produce Larabinoses [3]. In addition, exo-arabinanase (EC 3.2.1.-) is able to release terminal arabinose (non-reducing end with net retention of the anomeric configuration) or arabino-oligosaccharides from arabinan [8,9]. Based on the amino acid sequence similarities, endo-arabinanases and exo-arabinanases have been classified into glycoside hydrolase (GH) family 43 and GH93 family, respectively, whereas $\alpha$-L-arabinofuranosidases belong to five $\mathrm{GH}$ families (GH3, 43, 51, 54, 62) (http://www.cazy.org/). These arabinan-degrading enzymes from different $\mathrm{GH}$ families have presented various applications in industrial processes such as food technology, nutritional medical research and organic synthesis [4].

A few reports about the endo-arabinanases from bacteria and fungi have been published so far [5,6,8,10-19]. Among all the studies above, only a novel hyperthermophilic endo-arabinanase from Thermotoga petrophila was biophysically characterized and the three-dimensional (3D) structure was released $[1,17]$. Although the genome

rans 
of hyperthermophilic Thermotoga thermarum DSM 5069 has been sequenced, no information is currently available on the endo-arabinanase. In this study, a putative GH43 $\beta$-xylosidase from Thermotoga thermarum, Tth Abn, was cloned and expressed. Its biochemical characterization and application in arabinan degradation were also investigated. Upon the evaluation of substrate specificity, it was interesting to find that the recombinant enzyme was an endo-arabinanase, which has not yet been reported.

\section{Results}

\section{Amino acid sequence of Tth Abn}

The Tth abn gene isolated from the T. thermarum genome is $1,437 \mathrm{bp}$ in length coding for 479 amino acids. There is a signal peptide sequence (32 amino acids, $96 \mathrm{bp}$ ) in Tth Abn when analyzed by SignalP 4.0 (http://www.cbs. dtu.dk/services/SignalP/). Therefore, only the DNA fragment of 1,341 bp was amplified. Amino acid sequence of Tth Abn in GenBank is described as a putative $\beta$-xylosidase. However, it contains putative domains of $\alpha$ L-arabinofuranosidase (EC 3.2.1.55), endo-arabinanase (EC 3.2.1.99) and $\beta$-xylosidase (EC 3.2.1.37) through the BLAST. In this study, the provisional $\beta$-xylosidase was finally confirmed as an endo-arabinanase through the biochemical analysis. Tth Abn exhibited 64\% identity to the $\beta$-xylosidase from Thermotoga sp. RQ2 (GenBank accession number YP_001738698) and Thermotoga petrophila RKU-1 (GenBank accession number YP_001244233), 59\% identity to putative $\beta$-xylosidase Dictyoglomus thermophilum H-6-12 (GenBank accession number YP_002251442), and $50 \%$ identity to the endo-arabinanase from B. subtilis
Abn2 H318A mutant (GenBank accession number YP_002251442 2X8T). To gain insights into the evolutionary relationships among endo-arabinanases, the phylogenetic trees with 13 candidate sequences were constructed using the NJ and MP methods, respectively, which both supported the same topological structures as shown in Figure 1. Phylogenetic analysis indicated that Tth Abn from $T$. thermarum had a close relationship with an endo-arabinanase from T. petrophila and a putative $\beta$ xylosidase from the same genus $T$. sp.

Homology modeling revealed that Tth Abn had a similar 5 -fold $\beta$-propeller structure as the B. subtilis endo-arabinanase Abn2 H318A mutant [11] (Figure 2). Both sequence comparison and homology modeling indicated that $\mathrm{Asp}^{146}$ and $\mathrm{Glu}^{199}$ residues were the catalytic nucleophile and proton donor, respectively [11]. Furthermore, there are other conserved amino acid residues adjacent to the catalytic center, $\mathrm{His}^{9}, \mathrm{Asp}^{10}, \mathrm{Pro}^{11}, \mathrm{Trp}^{38}, \mathrm{Ala}^{73}$ and $\mathrm{Asn}^{143}$, which may play some roles in catalytic activity.

\section{Expression and purification of Tth Abn}

Mature protein coding 447 amino acids was successfully expressed in the cytoplasmatic fraction of E. coli BL21 (DE3). Then, the protein in the cell-free extract was purified by more than $95 \%$ homogeneity after heat treatment and affinity chromatography (Additional file 1: Table S1). Finally, the purified fusion enzyme showed a single band on a SDS-PAGE gel with an estimated molecular weight of $36 \mathrm{kDa}$ (Figure 3). To examine the oligomerization state of the enzyme, size exclusion

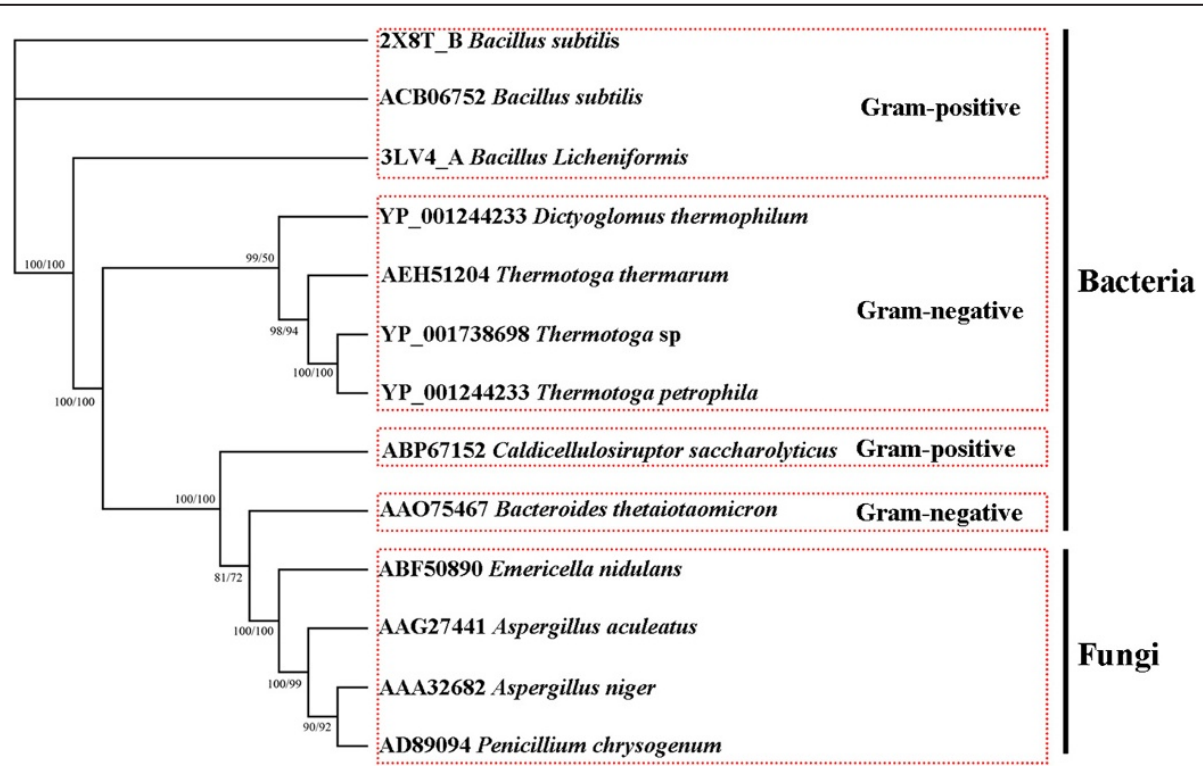

Figure 1 Neighbor-Joining (NJ) and Maximum-Parsimony (MP) trees resulted from analysis of endo-arabinanase with 13 amino acid sequences. Numbers on nodes correspond to percentage bootstrap values for 1000 replicates. The former confidence number in the Figure 1 is for $\mathrm{NJ}$ tree and the latter is for MP tree. 


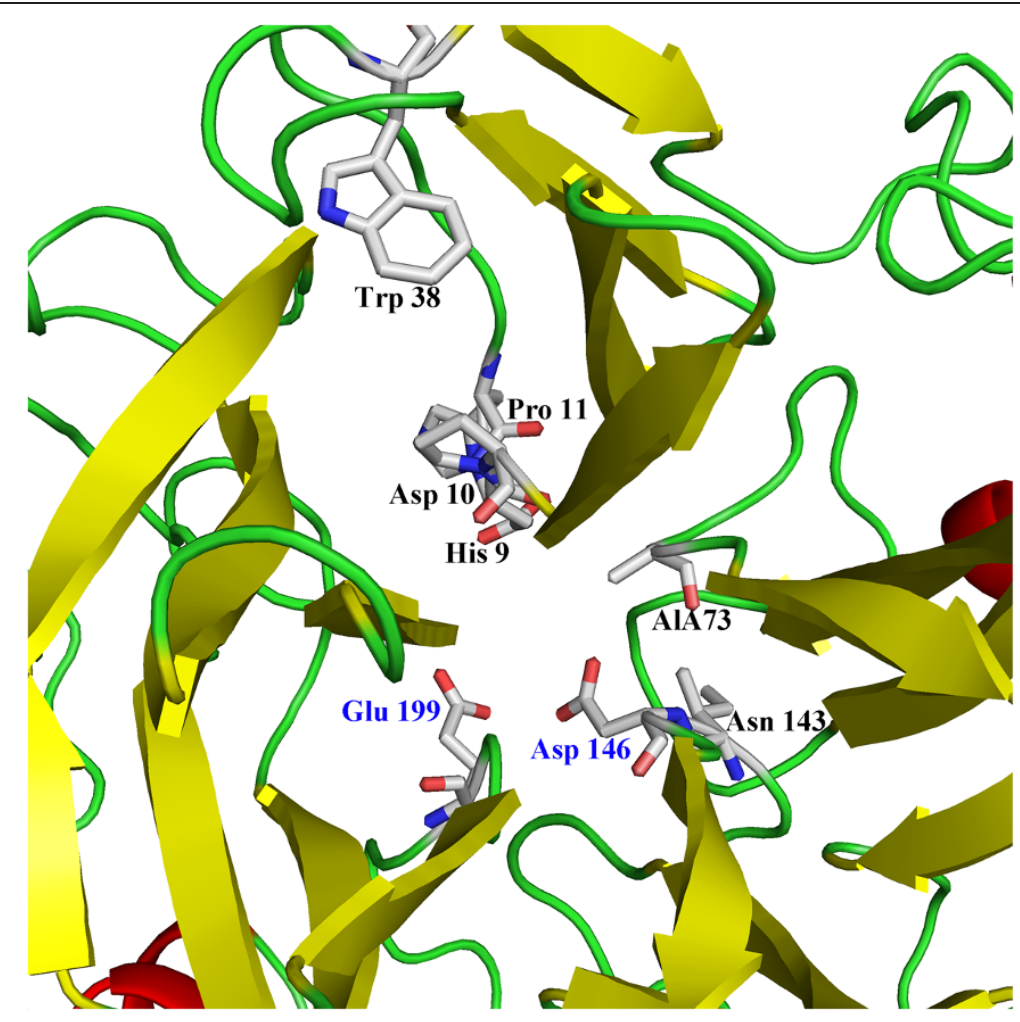

Figure 2 Predicted three-dimensional structure of Tth Abn. The potential catalytic amino acid residues are Asp ${ }^{146}$ and Glu $\mathrm{u}^{199}$.

chromatography was performed. The native protein formed monomer in solution with a calculated MW $35,622 \mathrm{Da}$ according to the calibration curve of the gel filtration column.

\section{Biochemical properties of Tth Abn}

Enzymatic characteristics of purified recombinant Tth Abn were determined and summarized in Tables 1, 2 and 3. Substrate specificity was assayed with different substrates (Table 1). It was interesting to find that Tth Abn was active towards linear arabinan, debranched arabinan and sugar beet arabinan, but there was no activity towards 1,4- $\beta$-D-mannan, galactan, $p$-Nitrophenyl- $\beta$-D-xylopyranoside $(p \mathrm{NPX})$, and $p$-nitrophenyl- $\alpha$-L-arabinofuranoside ( $p$ NPAF). These results indicated that the enzyme only exhibited arabinanase activity.

Effect of $\mathrm{pH}$ on Tth Abn activity was determined in $50 \mathrm{mM}$ imidazole-potassium buffer ranging from $\mathrm{pH} 5.5$ to 8.5 (Figure 4a). Tth Abn was found to exhibit an optimum activity at pH 6.5 and was able to retain more than $95 \%$ of its initial activity at $70^{\circ} \mathrm{C}$ for $1 \mathrm{~h}$ (Figure $4 \mathrm{~b}$ ). As a function of temperature, the enzyme displayed the highest activity at $75^{\circ} \mathrm{C}$ and retained more than $90 \%$ of its maximum activity even at $85^{\circ} \mathrm{C}$ after $10 \mathrm{~min}$ incubation (Figure 4c). Incubations at different temperatures to determine the enzyme's thermal stability were also carried out. As shown in the result, the enzyme kept nearly its initial activity at $75^{\circ} \mathrm{C}$ after $2 \mathrm{~h}$ incubation, and could still retain more than $80 \%$ of its original activity at $80^{\circ} \mathrm{C}$ for $2 \mathrm{~h}$ (Figure 4d).

Effects of metal ions and chemicals on Tth Abn activity were shown in Table 2 . In various assays, the enzyme activity was apparently stimulated by $1 \mathrm{mM} \mathrm{Mn}{ }^{2+}, \mathrm{Ca}^{2+}$, $\mathrm{Ba}^{2+}$, or chemical reagents $0.05 \%$ Tween 60 and $0.1 \%$ SDS. On the contrast, $\mathrm{Al}^{3+}, \mathrm{Cu}^{2+}$ and $\mathrm{Zn}^{2+}$ could inhibit the enzyme activity evidently. Kinetic studies in the presence of three arabinans as the substrates at optimum temperature and $\mathrm{pH}$ allowed the determination of the Michaelis-Menten parameters as shown in Table 3.

\section{Degradation of arabinan by Tth Abn}

Catalytic ability of Tth Abn on arabinan was investigated by analyzing the digestion products of linear, debranched and sugar beet arabinans (Figure 5a,b,c). Clearly from the result, the end products for hydrolysis of linear and debranched arabinans were arabinose, arabinobiose and arabinotriose after degradation for $3 \mathrm{~h}$. However, it displayed very weak catalytic ability towards the hydrolysis of sugar beet arabinan.

\section{Discussion}

Enzymatic hydrolysis of arabinose-linked hemicellulose in plant cell wall requires endo-arabinanase, arabinofuranosidase and arabinoxylan arabinofuranohydrolase, which 


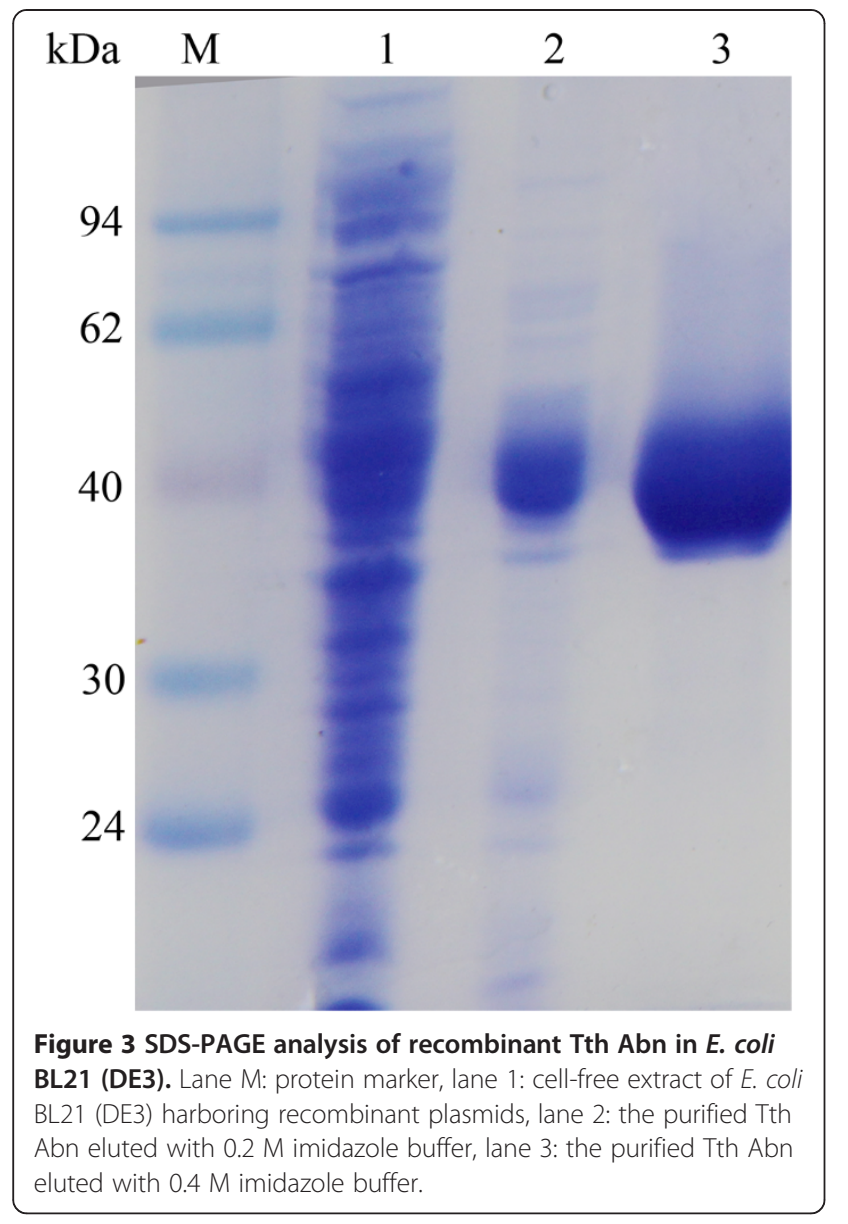

are capable of releasing arabinosyl oligomers and Larabinose from arabinose-containing polysaccharides [20].

We reported an endo-arabinanase (Tth Abn) from the hyperthermophilic bacterium $T$. thermarum here which was originally predicted as a $\beta$-xylosidase yet possessed the capability of arabinan depolymerization. Similar results have been published that endo-arabinanase from Thermotoga petrophila RKU-1 and B. subtilis were confirmed as endo-arabinanases through biophysical characterizations although once were predicted as $\beta$-xylosidases

Table 1 Specific activity of Tth Abn on various substrates

\begin{tabular}{|c|c|}
\hline Substrate & $\begin{array}{l}\text { Specific activity } \\
\left(\mu \mathrm{mol} \text { arabinose } \mathrm{min}^{-1} \mathrm{mg}^{-1}\right)\end{array}$ \\
\hline Linear arabinan & $237.7 \pm 10.0$ \\
\hline Debranched arabinan & $199.7 \pm 6.8$ \\
\hline Sugar beet arabinan & $42.5 \pm 1.5$ \\
\hline 1,4-ß-D-Mannan & ND \\
\hline Galactan & ND \\
\hline p-Nitrophenyl-a- $\mathrm{L}$-arabinofuranoside & ND \\
\hline p-Nitrophenyl- $\beta$-D-xylopyranoside & ND \\
\hline
\end{tabular}

ND: not detected. Values shown were the mean of triplicate experiments, and the variation about the mean was below $5 \%$.
Table 2 Effects of cations and chemical reagents on the activity of purified Tth Abn

\begin{tabular}{ll}
\hline Cations $^{\mathbf{a}} /$ Chemical reagents $^{\mathbf{b}}$ & Residual activity (\%) \\
\hline Control & $100 \pm 0.6$ \\
$\mathrm{Mg}^{2+}$ & $99 \pm 1.2$ \\
$\mathrm{Zn}^{2+}$ & $14 \pm 0.3$ \\
$\mathrm{Mn}^{2+}$ & $128 \pm 2.9$ \\
$\mathrm{Ba}^{2+}$ & $113 \pm 3.6$ \\
$\mathrm{Ca}^{2+}$ & $113 \pm 1.7$ \\
$\mathrm{Al}^{3+}$ & 0 \\
$\mathrm{Cu}^{2+}$ & 0 \\
$\mathrm{Co}^{2+}$ & $82 \pm 1.7$ \\
$\mathrm{Ni}^{2+}$ & $31 \pm 0.5$ \\
$\mathrm{Tween}^{2+} 60$ & $133 \pm 2.5$ \\
Tris & $41 \pm 0.4$ \\
$\mathrm{SDS}$ & $111 \pm 1.8$ \\
\hline
\end{tabular}

${ }^{\mathrm{a}}$ Final concentration, $1 \mathrm{mM}$. ${ }^{\mathrm{b}}$ Final concentration, 0.05\% Tween 60 and Tris, $0.1 \%$ SDS. Values shown were the mean of triplicate experiments, and the variation about the mean was below $5 \%$.

$[1,20]$. It is well known that hydrolases from GH43 family utilize a single displacement mechanism, which results in an inverted anomeric configuration for hydrolysis products [8]. Amino acid sequence alignment and homology modeling indicated that $\mathrm{Asp}^{146}$ and $\mathrm{Glu}^{199}$ in Tth Abn were the catalytic nucleophile (base) and proton donor, respectively. The result is also supported by the fact that aspartic acid and glutamic acid residues are the catalytic nucleophile and proton donor in all members of GH43 family (http://www.cazy.org). Residue Asp ${ }^{10}$ may act as a pKa modulator and maintain the correct alignment of the general acid residue relative to the substrate [21]. Residues $\mathrm{Asp}^{10}$, Asp ${ }^{146}$ and $\mathrm{Glu}^{199}$ located in the deep cavity at the centre of the $\beta$-propeller are also found in all members of GH32, 43, 62 and 68 [22]. As the consequence of the flexibility reduction of the polypeptide chain, residue Pro ${ }^{11}$ may contribute to the high thermal stability of the enzyme [23].

Phylogenetic analysis and enzymatic properties showed that Tth Abn was distant with the endo-arabinanases from Bacillus subtilis, Bacillus licheniformis and Aspergillus aculeatus $[4,5,19]$. However, it revealed a close relationship with $T$. thermarum and $T$. petrophila, indicating that they share the similar properties $[1,17]$. Other endoarabinanases from genus Thermotoga including $T$. thermarum endo-arabinanase have not yet been studied. Since there is $64 \%$ amino acid sequences similarity between endo-arabinanases T. thermarum and T. petrophila and is also inferred by the experimental data shown in Table 3, it is confirmed that Tth Abn could be an endo-arabinanase with some specific properties. 
Table 3 Characteristics of endo-arabinanases from T. thermarum DSM 5069 and other microorganisms

\begin{tabular}{|c|c|c|c|c|c|c|}
\hline Strain & $K_{m}\left(\mathrm{mg} \mathrm{ml}^{-1}\right)$ & 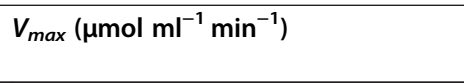 & $k_{\text {cat }}\left(\mathrm{s}^{-1}\right)$ & $k_{\text {cat }} / K_{m}\left(\mathrm{ml} \mathrm{mg}^{-1} \mathrm{~s}^{-1}\right)$ & $\begin{array}{l}\text { Optimal } \\
\text { temp }\left({ }^{\circ} \mathrm{C}\right)\end{array}$ & Reference \\
\hline $\begin{array}{l}\text { Thermotoga } \\
\text { thermarum }\end{array}$ & ${ }^{a_{1}} 12.3 \pm 0.15 b_{3.3 \pm 0.12} c_{2} 28.6 \pm 0.88$ & ${ }^{{ }^{a} 1,052.1 \pm 12.7} b_{510.9} b_{17.5} c_{164.0} 14.6$ & $a_{349.3 \pm 4.2}{ }^{b} 169.6 \pm 5.9 \quad c_{54.4} \pm 1.6$ & ${ }^{{ }^{a} 28.4 \pm 0.4}{ }^{b} 51.4 \pm 0.1 \quad{ }^{c} 1.9 \pm 0.0$ & 75 & This study \\
\hline $\begin{array}{l}\text { Caldicellulosiruptor } \\
\text { saccharolyticus }\end{array}$ & $b_{18.1}$ & ND & $b_{49.8}$ & $\mathrm{~b}_{2.8}$ & 75 & [3] \\
\hline Bacillus licheniformis & $b_{19} \pm 0.2$ & ND & $\mathrm{b}_{161 \pm 1.2}$ & $b_{8.47 \pm 0.16}$ & 35 & {$[5]$} \\
\hline Bacillus subtilis & ${ }^{\mathrm{a}} 2.0 \pm 0.24$ & ${ }^{a, d} 250 \pm 1.2$ & ND & ND & 50 & {$[20]$} \\
\hline Thermotoga petrophila & $b_{19.9} \pm 4.7$ & $\mathrm{~b}_{4} 48.2 \pm 63.6$ & ND & ND & 73 & [1] \\
\hline Aspergillus aculeatus & ${ }^{b} 66$ & 11 & ND & ND & 50 & [16] \\
\hline
\end{tabular}

ND: not determined. Data were carried out with linear arabinan (a), debranched arabinan (b), or sugar beet arabinan (c) as substrate. Values shown were the mean of triplicate experiments, and the variation about the mean was below $5 \%$. d: $\mu \mathrm{mol} \mathrm{mg}^{-1} \mathrm{~min}^{-1}$. 

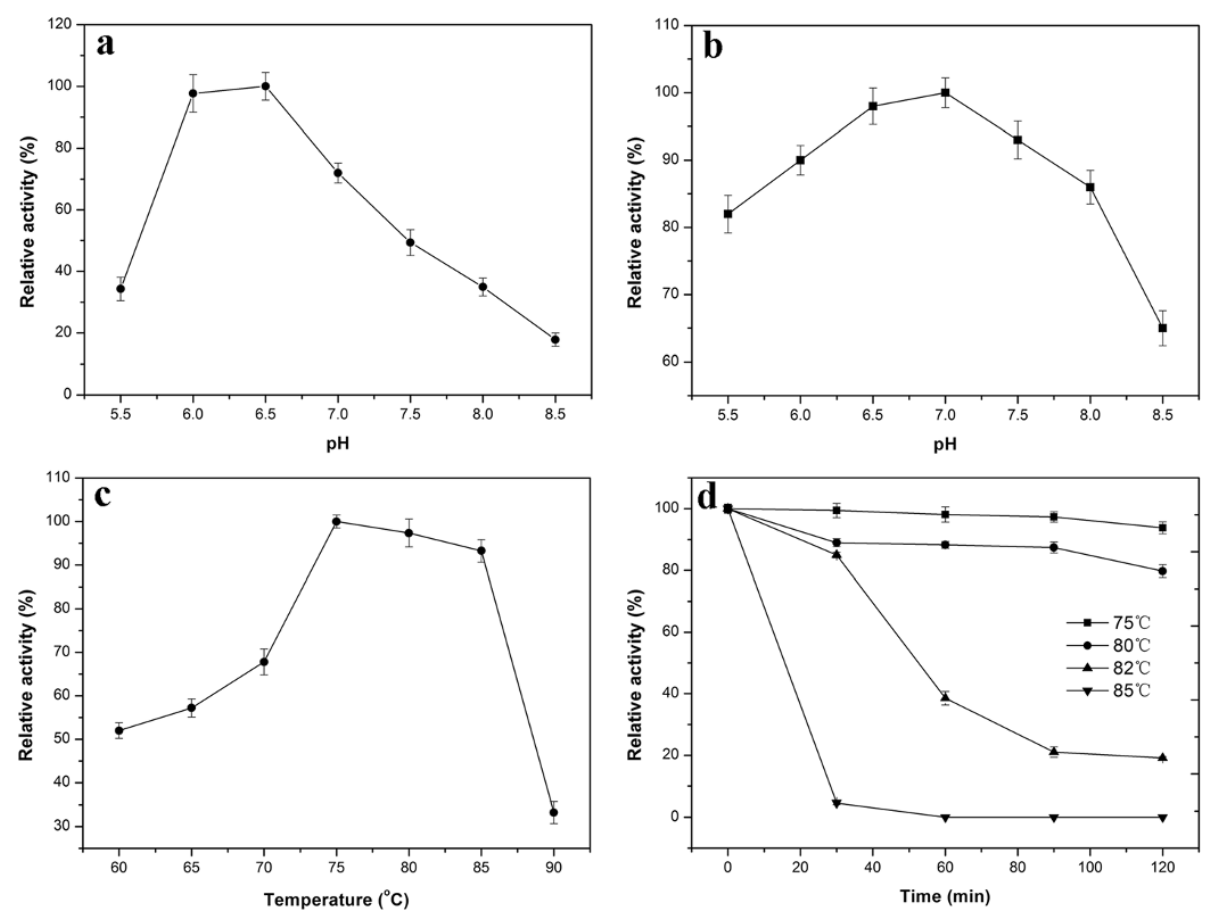

Figure 4 Effects of $\mathrm{pH}$ and temperature on the activity and stability of the recombinant Tth Abn endo-arabinanase. a. Optimal pH of the Tth Abn. b. pH stability of the Tth Abn. c. Effect of temperature on Tth Abn activity. $\mathbf{d}$. The thermostability of the Tth Abn. The residual activity was monitored, and the maximum activity was defined as $100 \%(\mathbf{a}, \mathbf{c})$ or initial activity was defined as $100 \%(\mathbf{b}$, d). Values shown were the mean of triplicate experiments, and the variation about the mean was below $5 \%$.

Tth Abn exhibited good thermostability when incubated at $75^{\circ}$ for $2 \mathrm{~h}$. Endo-arabinanase from Gram-negative bacterium T. petrophila RKU-1 has been reported to have a $\mathrm{pH}$ optimum at 6.5 and retained $95 \%$ of initial activity at $90^{\circ} \mathrm{C}$ for $10 \mathrm{~h}$ [1]. While Gram-positive bacteria B. subtilis and $B$. licheniformis endo-arabinanases show optimum activity at near-neutral $\mathrm{pH}$ at $60^{\circ} \mathrm{C}$ and $35^{\circ} \mathrm{C}$, respectively [4]. Endo-arabinanase Aspergillus aculeatus from fungus displays optimum activity at $\mathrm{pH} 5.5$ and $50^{\circ} \mathrm{C}$ [16]. In general, endo-arabinanases from bacteria exhibit the nearneutral $\mathrm{pH}$ optima, while those from fungi display the acid
$\mathrm{pH}$ optima. The enzyme activities regarding $\mathrm{pH}$ from bacteria and fungi are also consistent with their inherent properties.

Cations and chemical reagents exhibited different effects on the activity of the endo-arabinanase Tth Abn. With the evidence that one $\mathrm{Ca}^{2+}$ ion was observed in the catalytic cavity of Bacillus subtilis about $5 \AA$ below the catalytic carboxylates and the presence of ions in an equivalent location in other arabinanases [22].

Compared to other endo-arabinanases, Tth Abn demonstrated the highest $V_{\max }$ value among all the known

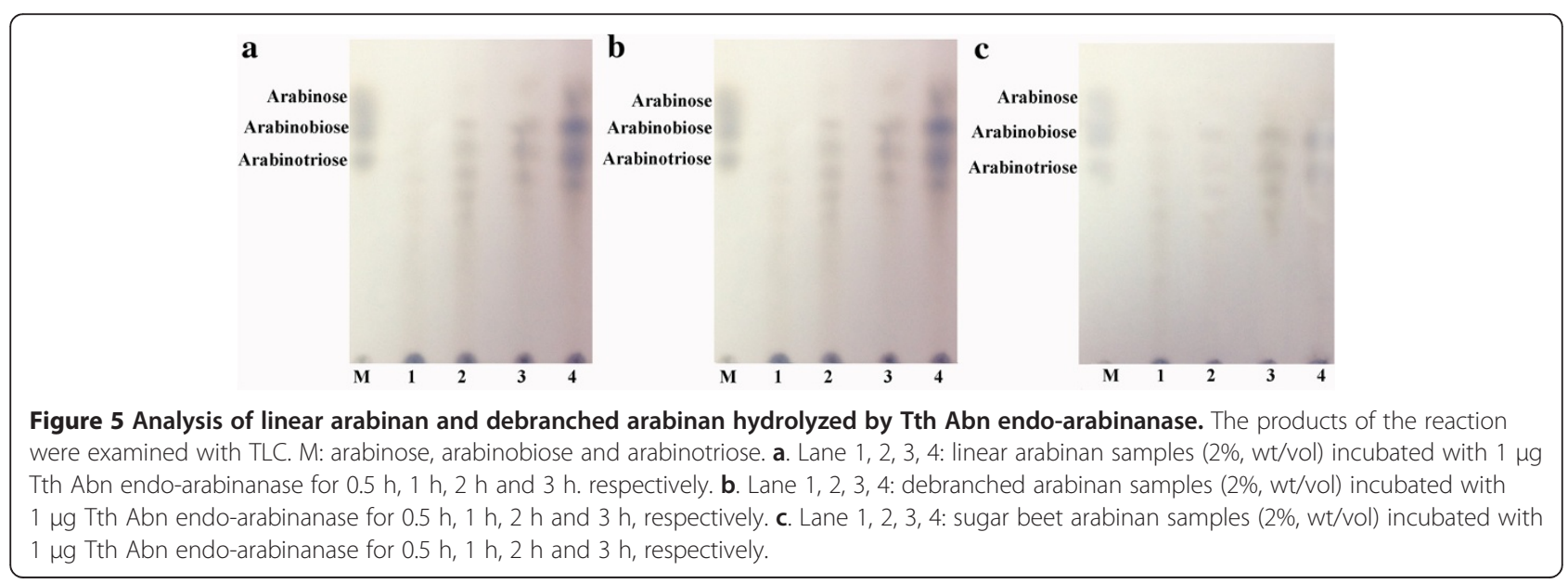


endo-arabinanases from thermophile and hyperthermophile when linear arabinan was used as the substrate. The catalytic efficiency $\left(k_{c a t} / K_{m}\right)$ of endo-arabinanase Tth Abn on debranched arabinanwas approximately 6-fold and 18fold higher than B. licheniformis and Caldicellulosiruptor saccharolyticus, respectively (Table 3 ). In addition, catalytic efficiency for linear, debranched and sugar beet arabinans existed obvious differences (linear $>$ debranched $>$ sugar beet). This may be caused by substrate's composition and structure. As we know, a typical sugar composition of linear arabinan is: arabinose: galactose: rhamnose: galacturonic acid = 97.5: 0.4: 0.1: 2.0. For debranched and sugar beet arabinans, the contents of arabinose are lower than linear arabinan, and sugar beet arabinan has more substitutions attached to backbone while 1,2- and 1,3- $\alpha$-L-arabinofuranosyl branch units of debranched arabinan have been all removed.

The fact that Tth Abn could hydrolyze linear and debranched arabinan into oligomers arabinose, arabinobiose and arabinotriose implied that the Tth Abn had endoarabinanase activity but no exo activity. Only a few endoarabinanases especially that from hyperthermophile have been reported to possess the function in generating arabino-oligosaccharides [1,17]. Although it was insensitive to the branched arabinan (eg. sugar beet arabinan), Tth Abn could be used together with other arabinandegrading enzymes in synergistic reaction for the hydrolysis of branched ones.

\section{Conclusions}

In this study, a useful endo-arabinanase (Tth Abn) from T. thermarum DSM 5069 was expressed in E. coli with desirable features, such as high thermostability, catalytic efficiency, and hydrolytic reaction at high temperature. This is easily envisioned that Tth Abn endo-arabinanase exhibits a great potential for enzymatic conversion of arabinan through synergetic action with other arabinandegrading enzymes.

\section{Methods}

\section{Substrates}

Linear arabinan, debranched arabinan, sugar beet arabinan, 1,4- $\beta$-D-mannan and galactan were purchased from Megazyme (Wicklow, Ireland). $p$ NPX and $p$ NPAF were purchased from Sigma Chemical Co., Ltd. (St. louis, USA).

\section{Bacterial strains and growth conditions}

E. coli Top10 (Novagen, San Diego, USA) was used for routine molecular cloning work and E. coli BL21 (DE3) (Novagen) was employed as the host for the expression of the recombinant Tth Abn. E. coli strains, both were grown in Luria-Bertani (LB) medium. Ampicillin $\left(100 \mu \mathrm{g} \mathrm{ml}{ }^{-1}\right.$,
Shanghai, China) and isopropyl- $\beta$-D-thiogalactopyranoside (IPTG, $0.5 \mathrm{mM}$, Dalian, China) were added when necessary.

\section{Construction of plasmids and strains}

DNA manipulations were carried out according to standard methods [24]. Restriction enzymes and high-fidelity Ex-Taq DNA polymerase were purchased from Takara Biotechnology Co. Ltd. (Dalian, China) and used according to the manufacturer's instructions. DNA was extracted from agarose gels with BIOMIGA Gel Extraction Kit (Shanghai, China). Sequencing was performed using ABI 3730 DNA analyzer (Applied Biosystems, Foster City, USA). PCR amplifications were conducted using highfidelity Ex-Taq DNA polymerase, and the resulting products were purified with BIOMIGA PCR Purification Kit (Shanghai, China).

The coding sequence of Tth abn gene was amplified from $T$. thermarum genomic DNA using primers 5'GGAATTCCATATGGTATTCAACTGGGCAACTGTACAC-3' (forward) and 5'- CCGCTCGAGATCTTCGA TCCGAACTCCCCAG-3' (reverse). The primers contained restrictions sites $N d e \mathrm{I}$ and $\mathrm{XhoI}$ (underlined) for forward and reverse primers, respectively. The amplified DNA fragment was digested with NdeI and XhoI, and inserted into the corresponding sites in plasmid pET-20b (Novagen) to produce pET-20b-Tth abn. The correctness of the insert was confirmed by DNA sequencing.

\section{Expression and purification of recombinant Tth Abn}

E. coli BL21 (DE3) cells harboring recombinant plasmids were grown $\left(200 \mathrm{rpm}, 37^{\circ} \mathrm{C}\right)$ in $\mathrm{LB}$ medium $(200 \mathrm{ml})$ with appropriate antibiotic selection. When the $\mathrm{OD}_{600}$ reached $0.6 \sim 0.8$, the expression of Tth Abn was induced by the addition of $0.5 \mathrm{mM}$ IPTG and the culture was further incubated $\left(150 \mathrm{rpm}, 25^{\circ} \mathrm{C}, 12 \mathrm{~h}\right)$. Cells were harvested by centrifugation $\left(10000 \mathrm{rpm}, 4^{\circ} \mathrm{C}, 5 \mathrm{~min}\right)$. The pellet was washed twice with $20 \mathrm{mM}$ Tris- $\mathrm{HCl}$ buffer ( $\mathrm{pH} 8.0$ ), and re-suspended in $5 \mathrm{ml}$ of $5 \mathrm{mM}$ imidazole, $0.5 \mathrm{mM} \mathrm{NaCl}$, and $20 \mathrm{mM}$ Tris- $\mathrm{HCl}$ buffer ( $\mathrm{pH}$ 7.9). All steps were carried out at $4^{\circ} \mathrm{C}$. The cell extracts after sonication were heat treated at $70^{\circ} \mathrm{C}$ for $30 \mathrm{~min}$, and subsequently cooled in an ice bath. After centrifugation $\left(15000 \mathrm{~g}, 4^{\circ} \mathrm{C}, 20 \mathrm{~min}\right)$, the resulting supernatant was loaded onto a $1 \mathrm{ml}$ nickle affinity column (Novagen) and the bounded proteins were eluted by discontinuous imidazole gradient (30-1000 mM). The fractions that contained Tth Abn were dialyzed overnight against storage buffer $(20 \mathrm{mM}$ Na-phosphate, $50 \mathrm{mM}$ $\mathrm{NaCl}, 10 \%$ glycerol, $\mathrm{pH} 7.0$ ) and then were kept at $-80^{\circ} \mathrm{C}$ until further use. The analysis of production and purity of the enzymes were determined by a 12\% SDS-PAGE gel [25] using broad range molecular weight markers (MBI Fermemtas, Burlington, Canada) as standards. The protein concentration was determined by Bradford method using bovine serum albumin (BSA) as a standard 
[26]. Oligomerization state of Tth Abn was analyzed by size exclusion chromatography on a AKTAFPLC $C^{\mathrm{mm}}$ (GE Healthcare Life Sciences, New Jersey, USA) system with a Superdex 200 10/30 GL column as described by Zhang et al. [27].

\section{Biochemical characterization}

Unless otherwise stated, all the enzyme-catalyzed reactions were performed at $75^{\circ} \mathrm{C}$ for $10 \mathrm{~min}$ in $50 \mathrm{mM}$ imidazole-potassium buffer ( $\mathrm{pH}$ 6.5) containing $0.1 \mu \mathrm{g}$ enzyme and $0.4 \%(\mathrm{w} / \mathrm{v})$ linear arabinan. The total reaction system was $0.2 \mathrm{ml}$. The reducing sugar content after hydrolysis of the polysaccharides was determined by the 3,5-dinitrosalicylic acid method [28] with L-arabinose as the standard. One enzyme activity unit was defined as the amount of enzyme producing $1 \mu \mathrm{mol}$ of arabinose per minute. All assays were performed in triplicate.

Optimum temperature and $\mathrm{pH}$ for enzymatic activity of the Tth Abn were examined with linear arabinan 0.4\% $(\mathrm{w} / \mathrm{v})$ as substrate for $10 \mathrm{~min}$. The effect of $\mathrm{pH}$ on the activity was tested at $\mathrm{pH} 5.5$ to 8.5 in $50 \mathrm{mM}$ imidazolepotassium buffer at $75^{\circ} \mathrm{C}$. The effect of temperature was assayed at temperatures ranging from $60^{\circ} \mathrm{C}$ to $95^{\circ} \mathrm{C}$ in $50 \mathrm{mM}$ imidazole-potassium buffer at $\mathrm{pH}$ 6.5. The $\mathrm{pH}$ stability was determined from $\mathrm{pH} 5.5$ to 8.5 at $75^{\circ} \mathrm{C}$ for $1 \mathrm{~h}$. Thermostability of the enzyme was estimated by incubating the diluted solution of enzyme at different temperatures $\left(75^{\circ} \mathrm{C}, 80^{\circ} \mathrm{C}, 82^{\circ} \mathrm{C}\right.$ and $\left.85^{\circ} \mathrm{C}\right)$. Samples were removed after different time intervals (30 min, $60 \mathrm{~min}, 90 \mathrm{~min}$, and $120 \mathrm{~min}$ ) and kept in ice for $10 \mathrm{~min}$.

Enzymatic activity was also examined in the presence of metal ions and chemical reagents. Magnesium chloride $\left(\mathrm{MgCl}_{2}\right)$, zinc sulfate $\left(\mathrm{ZnSO}_{4}\right)$, barium chloride $\left(\mathrm{BaCl}_{2}\right)$, nickel sulfate $\left(\mathrm{NiSO}_{4}\right)$, manganese chloride $\left(\mathrm{MnCl}_{2}\right)$, calcium chloride $\left(\mathrm{CaCl}_{2}\right)$, cobalt chloride $\left(\mathrm{CoCl}_{2}\right)$, copper sulfate $\left(\mathrm{CuSO}_{4}\right)$ or aluminum sulfate $\left(\mathrm{Al}_{2}\left(\mathrm{SO}_{4}\right)_{3}\right)$ were used at a concentration of $1 \mathrm{mM}$, and the chemical reagents Tween 60, Tris or sodium dodecyl sulfate (SDS) were added at $0.05 \%, 0.05 \%$ and $0.1 \%$, respectively in the reaction mixture. The enzyme was incubated with each cation or reagent at $80^{\circ} \mathrm{C}$ for $2 \mathrm{~h}$ before the addition of linear arabinan $0.4 \%(\mathrm{w} / \mathrm{v})$ to initiate the enzyme reaction. The activity of the enzyme without adding chemical reagent or metal ion was defined as $100 \%$. The kinetic parameters, apparent $K_{m}$ and $V_{\max }$ values were calculated according to the Lineweaver-Burk method at optimum $\mathrm{pH}$ and temperature using linear arabinan as substrate at concentrations ranging from 1.25 to $30 \mathrm{mg} \mathrm{ml}^{-1}$.

\section{Substrate specificity and degradation}

The abilities of the enzyme to hydrolyze the natural and modified substrates, including linear arabinan, debranched arabinan, sugar beet arabinan, 1,4- $\beta-\mathrm{D}-$ mannan, galactan, $p$ NPX and $p$ NPAF, were measured at $75^{\circ} \mathrm{C}$ for various time $(0.5 \mathrm{~h}, 1 \mathrm{~h}, 2 \mathrm{~h}$ and $3 \mathrm{~h})$. The reaction mixture $(600 \mu \mathrm{L})$ contained $2 \%$ substrate $(\mathrm{wt} / \mathrm{vol})$ and $1 \mu \mathrm{g}$ enzyme in $50 \mathrm{mM}$ imidazole-potassium buffer ( $\mathrm{pH}$ 6.5). The reaction was stopped by cooling the mixture at $4^{\circ} \mathrm{C}$ in a water bath. Thin-layer chromatography (TLC) was applied to monitor the degradation of linear arabinan using arabinose, arabinobiose and arabinotriose as the standard markers. TLC was performed using G plates (Qingdao, China) with a mobile phase containing $n$-butanol/acetic acid/water (3:1:1). The sugars that degraded were detected using the orcinol/concentrated sulfuric acid reagent [29].

\section{Bioinformatics analysis}

Multiple sequence alignment was conducted using Clustal X2 [30]. Phylogenetic relationships were deduced using the Neighbor-Joining (NJ) and Maximum-Parsimony (MP) methods as performed in PAUP 4.0 [31]. Homology modeling was performed using Swiss Model [32-34]. The crystal structure of a GH43 endo-arabinanase from Bacillus subtilis (PDB entry code: 2X8T) was used as threedimensional template for restraint-based modeling as implemented in SPDBV_4.04_PC.

\section{Nucleotide sequence accession number}

GenBank accession number of the T. thermarum DSM5069 endoarabinanase is AEH51204.

\section{Additional file}

\section{Additional file 1: Supplementary Information.}

\section{Competing interests}

The authors declare that they have no competing interests.

\section{Authors' contributions}

HS carried out the cloning and expression and drafted the manuscript. HD, $Y H, L W$, and $X L$ helped to purify and characterize the Tth Abn. YZ helped to revise the manuscript. FW directed the overall study and revised the manuscript. All authors have read and approved the final manuscript.

\section{Acknowledgements}

This work was financially supported by the National Natural Science Foundation of China (No. 31170537, 31370572), Jiangsu Provincial Government (CXZZ11_0526), and the Doctorate Fellowship Foundation of Nanjing Forestry University as well as the Priority Academic Program Development of Jiangsu Higher Education Institutions (PAPD).

\section{Received: 8 October 2013 Accepted: 24 April 2014}

Published: 30 April 2014

\section{References}

1. Squina FM, Santos CR, Ribeiro DA, Cota J, de Oliveira RR, Ruller R, Mort A, Murakami MT, Prade RA: Substrate cleavage pattern, biophysical characterization and low-resolution structure of a novel hyperthermostable arabinanase from Thermotoga petrophila. Biochem Biophys Res Commun 2010, 399:505-511.

2. Himmel ME, Ding SY, Johnson DK, Adney WS, Nimlos MR, Brady JW, Foust TD: Biomass recalcitrance: Engineering plants and enzymes for biofuels production. Science 2007, 315:804-807. 
3. Hong MR, Park CS, Oh DK: Characterization of a thermostable endo-1,5-a-l-arabinanase from Caldicellulorsiruptor saccharolyticus. Biotechnol Lett 2009, 31:1439-1443.

4. Leal TF, Sá-Nogueira I: Purification, characterization and functional analysis of an endo-arabinanase (AbnA) from Bacillus subtilis. FEMS Microbiol Lett 2004, 241:41-48.

5. Seo ES, Lim YR, Kim YS, Park CS, Oh DK: Characterization of a recombinant endo-1,5-a-l-arabinanase from the isolated bacterium Bacillus licheniformis. Biotechnol Bioprocess Eng 2010, 15:590-594.

6. Sakamoto T, Ihara H, Kozaki S, Kawasaki H: A cold-adapted endo-arabinanase from Penicillium chrysogenum. Biochim Biophys Acta Gen Subj 2003, 1624:70-75.

7. Sanchez S, Demain AL: Enzymes and Bioconversions of Industrial, Pharmaceutical, and Biotechnological Significance. Org Process Res Dev 2011, 15:224-230.

8. Wong DWS, Chan VJ, Batt SB: Cloning and characterization of a novel exo-a-1,5-L-arabinanase gene and the enzyme. Appl Microbiol Biotechnol 2008, 79:941-949.

9. Carapito R, Imberty A, Jeltsch JM, Byrns SC, Tam PH, Lowary TL, Varrot A, Phalip V: Molecular basis of arabinobio-hydrolase activity in phytopathogenic fungi crystal structure and catalytic mechanism of Fusarium graminearum GH93 exo-alpha-L-arabinanase. J Biol Chem 2009, 284:12285-12296.

10. Kaji A, Saheki T: Endo-arabinanase from Bacillus subtilis F-11. Biochim Biophys Acta 1975, 410:354-360.

11. de Sanctis D, Bento I, Inacio JM, Custodio S, de Sá-Nogueira I, Carrondo MA: Overproduction, crystallization and preliminary X-ray characterization of Abn2, an endo-1,5-alpha-arabinanase from Bacillus subtilis. Acta Crystallographica Section F-Structural Biology and Crystallization Communications 2008, 64:636-638.

12. Dunkel MP, Amado R: Analysis of endo-(1->5)-alpha-L-arabinanase degradation patterns of linear (1->5)-alpha-L-arabino-oligosaccharides by high-performance anion-exchange chromatography with pulsed amperometric detection. Carbohydr Res 1995, 268:151-158.

13. McKie VA, Black GW, Millward-Sadler SJ, Hazlewood GP, Laurie Jl, Gilbert HJ: Arabinanase A from Pseudomonas fluorescens subsp cellulosa exhibits both an endo- and an exo- mode of action. Biochem J 1997, 323(Pt 2):547-555.

14. Nurizzo D, Turkenburg JP, Charnock SJ, Roberts SM, Dodson EJ, McKie VA, Taylor EJ, Gilbert HJ, Davies GJ: Cellvibrio japonicus alpha-L-arabinanase 43A has a novel five-blade beta-propeller fold. Nat Struct Biol 2002, 9:665-668.

15. Scott M, Pickersgill RW, Hazlewood GP, Gilbert HJ, Harris GW: Crystallization and preliminary X-ray analysis of arabinanase A from Pseudomonas fluorescens subspecies cellulosa. Acta crystallographica Section D, Biological crystallography 1999, 55:544-546.

16. Skjot M, Kauppinen S, Kofod LV, Fuglsang C, Pauly M, Dalboge H, Andersen LN: Functional cloning of an endo-arabinanase from Aspergillus aculeatus and its heterologous expression in A. oryzae and tobacco. Mol Gen Genomics 2001, 265:913-921.

17. Squina FM, Prade RA, Wang HL, Murakami MT: Expression, purification, crystallization and preliminary crystallographic analysis of an endo-1,5-alpha-L-arabinanase from hyperthermophilic Thermotoga petrophila. Acta Crystallographica Section F-Structural Biology and Crystallization Communications 2009, 65:902-905.

18. Yamaguchi A, Tada T, Nakaniwa T, Kitatani T, Takao M, Sakai T, Nishimura K Crystallization and preliminary $\mathrm{X}$-ray diffraction analysis of a thermostable endo-1,5-alpha-L-arabinanase from Bacillus thermodenitrificans TS-3. Acta Crystallographica Section D-Biological Crystallography 2004, 60:1149-1151.

19. Yamaguchi A, Tada T, Wada K, Nakaniwa T, Kitatani T, Sogabe Y, Takao M, Sakai T, Nishimura K: Structural basis for thermostability of endo-1,5-alpha-L-arabinanase from Bacillus thermodenitrificans TS-3. J Biochem 2005, 137:587-592.

20. Inacio JM, de Sá-Nogueira I: Characterization of abn2 (yxiA), Encoding a Bacillus subtilis GH43 Arabinanase, Abn2, and Its Role in Arabino-Polysaccharide Degradation. J Bacteriol 2008, 190:4272-4280.

21. de Sanctis D, Inacio JM, Lindley PF, de Sá-Nogueira I, Bento I: New evidence for the role of calcium in the glycosidase reaction of $\mathrm{GH} 43$ arabinanases. FEBS J 2010, 277:4562-4574.
22. Pons T, Naumoff DG, Martinez-Fleites $C$, Hernandez L: Three acidic residues are at the active site of a beta-propeller architecture in glycoside hydrolase families 32, 43, 62, and 68. Proteins-Structure Function and Bioinformatics 2004, 54:424-432.

23. Watanabe K, Kitamura K, Suzuki Y: Analysis of the critical sites for protein thermostabilization by proline substitution in oligo-1,6-glucosidase from Bacillus coagulans ATCC 7050 and the evolutionary consideration of proline residues. Appl Environ Microbiol 1996, 62:2066-2073.

24. Mahuku GS: A simple extraction method suitable for PCR-based analysis of plant, fungal, and bacterial DNA. Plant Mol Biol Report 2004, 22:71-81.

25. Lammirato C, Miltner A, Kaestner M: Effects of wood char and activated carbon on the hydrolysis of cellobiose by $\beta$-glucosidase from Aspergillus niger. Soil Biol Biochem 2011, 43:1936-1942.

26. Laemmli UK: Cleavage of structural proteins during the assembly of the head of bacteriophage T4. Nature 1970, 227:680-685.

27. Zhang Y, Raudah S, Teo H, Teo GWS, Fan R, Sun X, Orner BP: Alanine-shaving mutagenesis to determine key interfacial residues governing the assembly of a nano-cage maxi-ferritin. J Biol Chem 2010, 285:12078-12086.

28. Miller $G L$ : Use of dinitrosalicylic acid reagent for determination of ruducing sugar. Anal Chem 1959, 31:426-428.

29. Okuyama M, Okuno A, Shimizu N, Mori H, Kimura A, Chiba S: Carboxyl group of residue Asp647 as possible proton donor in catalytic reaction of alpha-glucosidase from Schizosaccharomyces pombe. Eur J Biochem 2001, 268:2270-2280.

30. Larkin MA, Blackshields G, Brown NP, Chenna R, McGettigan PA, McWilliam H, Valentin F, Wallace IM, Wilm A, Lopez R, Thompson JD, Gibson TJ, Higgins DG: Clustal W and clustal X version 2.0. Bioinformatics 2007, 23:2947-2948.

31. Wilgenbusch JC, Swofford D: Inferring evolutionary trees with PAUP*. Curr Protoc Bioinformatics 2003. Chaper 6, unit 6.4. http://www.currentprotocols. com/protocol/bi0604.

32. Schwede T, Kopp J, Guex N, Peitsch MC: SWISS-MODEL: an automated protein homology-modeling server. Nucleic Acids Res 2003, 31:3381-3385.

33. Guex N, Peitsch MC: SWISS-MODEL and the Swiss-PdbViewer: an environment for comparative protein modeling. Electrophoresis 1997, 18:2714-2723.

34. Arnold K, Bordoli L, Kopp J, Schwede T: The SWISS-MODEL workspace: a web-based environment for protein structure homology modelling. Bioinformatics 2006, 22:195-201.

doi:10.1186/1472-6750-14-35

Cite this article as: Shi et al: Expression and characterization of a GH43 endo-arabinanase from Thermotoga thermarum. BMC Biotechnology 2014 14:35.

\section{Submit your next manuscript to BioMed Central and take full advantage of:}

- Convenient online submission

- Thorough peer review

- No space constraints or color figure charges

- Immediate publication on acceptance

- Inclusion in PubMed, CAS, Scopus and Google Scholar

- Research which is freely available for redistribution 